\title{
BEHAVIOUR OF LARVAE ON DIETS CONTAINING BACILLUS THURINGIENSIS FORMULATIONS OR ENDOTOXINS
}

\author{
M.O. HARRIS, F. MAFILEíO and S. DHANA
}

\author{
The Horticulture and Food Research Institute of New Zealand Ltd, Private Bag 92169, \\ Auckland, New Zealand
}

\begin{abstract}
Behavioral responses of individual lightbrown apple moth, Epiphyas postvittana (Walker), neonate larvae to Dipel or the Bacillus thuringiensis delta endotoxins CryIAc and Cry1Ba incorporated into artificial diets were measured in choice and no-choice treatments. Frass production and the spinning of silken shelters were delayed when larvae were given diets containing Dipel or Bt endotoxins. In choice treatments larvae did not exhibit an initial preference for control diets over diets with Dipel or Bt endotoxins but accumulated on control diets over a period of days, apparently because larvae that first settled on Dipel or endotoxin diets abandoned diets while larvae that fed on control diets remained on diets throughout the experiment. Abandonment of diets containing Dipel or endotoxins was also apparent in nochoice treatments. Larvae exposed to such diets were more likely to be observed walking or at different sites from one observation to the next, and produced frass and silken feeding shelters at multiple sites rather than a single site. The implications of these findings for the use of $B$. thuringiensis as a commercial spray or for the use of $B$. thuringiensis endotoxin genes as resistance factors to be expressed in transgenic apples are discussed.
\end{abstract}

\section{INTEGRATED FRUIT PRODUCTION IN ACTION: PROFILE OF A CANTERBURY ORCHARD}

\author{
G.M. BURNIP ${ }^{1}$, D.M. SUCKLING ${ }^{1}$, A.R. GIBB $^{1}$ and W. MOTTRAM ${ }^{2}$ \\ ${ }^{1}$ HortResearch, PO Box 51, Lincoln \\ ${ }^{2}$ Mottram's Orchard, RD 6, Prebbleton
}

Monitoring of pest and disease incidence was carried out on a Canterbury gate-sales orchard using the New Zealand Integrated Fruit Production for pipfruit (NZ IFP-P) production protocols, during the 1996-97 season. All apple blocks received an application of chlorpyrifos and oil, at green-tip. The lepidopteran specific insecticide, tebufenozide, provided adequate season long control of codling moth and leafroller. A single application was applied to early apple cultivars and two applications to the mid- and late-season cultivars. Insect sampling procedures as detailed in the NZ IFP-P manual were used throughout the season. Monthly samples indicated that woolly apple aphid and leafcurling midge remained below the thresholds set for these pests. No post-bloom organophosphate insecticides were applied, except to several rows of newly grafted trees, where diazinon was used to reduce leafcurling midge populations. Fungicide applications were reduced compared to previous years (2 DMI fungicides), through using the NZ IFP-P guidelines. Fruit samples at harvest showed that the incidence of insect and disease damaged fruit was very low. This illustrates that Canterbury apple orchards are able to produce quality fruit while utilising the low inputs of this integrated system. 